\title{
Regeneration of New Neurons Is Preserved in Aged Vomeronasal Epithelia
}

\author{
Jessica H. Brann ${ }^{1}$ and Stuart Firestein ${ }^{1,2}$ \\ ${ }^{1}$ Department of Biological Sciences and 2Department of Neuroscience, Columbia University, New York, New York 10027
}

During normal and diseased aging, it is thought the capacity for tissue regeneration and repair in neuronal tissues diminishes. In the peripheral olfactory system, stem cell reservoirs permit regeneration of olfactory and vomeronasal sensory neurons, a unique capacity among neurons. Following injury, a large number of new neurons can be regenerated in a young animal. However, it is unknown whether this capacity for renewal exists in aged proliferative populations. Here, we report that neuronal replacement-associated proliferation continues in the vomeronasal organ of aged (18-24 months) mice. In addition, the potential for the aged stem cell to yield a mature neuron persisted at the same rate as that observed in young animals. Furthermore, the robust regenerative capacity to respond to both acute and sustained injury following olfactory bulbectomy remains intact even in very old animals. Hence, the neuronal epithelium lining the vomeronasal organ is unique in that it contains stem cells capable of generating functional neurons throughout life and in the aged animal in particular. This persistent regenerative capacity provides hope for neuronal replacement therapies in the aged nervous system.

\section{Introduction}

Stem cell technology and therapy present particular difficulties in the nervous system since virtually all stem cell activity ceases relatively early in the brain's development. There are a few exceptions, including the subgranular and subventricular proliferative zones that supply new neurons to the hippocampus and the olfactory bulb, respectively (Whitman and Greer, 2009). However, the cells in these regions of the brain are difficult to purify and manipulate; they may have diminished future therapeutic value because of their apparently programmed identity. In addition to these regions, the epithelium that lines the vomeronasal organ (VNO) contains cells capable of lifelong proliferation.

During normal and diseased aging, it is thought the capacity for regeneration and repair in neuronal tissues diminishes (Mimeault and Batra, 2009) due to impairments in gene expression and the function of the stem cell population (Bailey et al., 2004; Ahlenius et al., 2009; Wagner et al., 2009). Olfactory epithelia are unique in that stem cell reservoirs permit regeneration of olfactory and vomeronasal sensory neurons and that the generated cells are excitatory projection neurons (Graziadei and Monti Graziadei, 1983; Halpern and Martínez-Marcos, 2003). Until recently, studies of the effects of aging and neuronal regeneration have generally been limited to animals no older than $2-3$ months of age with little attention given to aged adult animal models. It is likely that stem cell therapies will require isolation

\footnotetext{
Received Aug. 17, 2010; revised Sept. 11, 2010; accepted Sept. 27, 2010.

This work was supported by National Institute on Deafness and Other Communication Disorders Grant F32 DC008455 (to J.H.B.) and National Institute on Aging Grant P01AG028054 (to S.F.). We thank the members of the Firestein Laboratory for their thoughtful comments and advice. We thank Jenny Shen for histological help, Zita Peterlin for help in generating illustrations, and Matthew Valley for help in generating heat maps.

Correspondence should be addressed to either Dr. Jessica H. Brann or Dr. Stuart Firestein, 923 Fairchild Building, MC 2439, Department of Biological Sciences, Columbia University, New York, NY 10027. E-mail: jb2602@ columbia.edu or sjf24@columbia.edu.

D0I:10.1523/JNEUROSCI.4316-10.2010

Copyright $\odot 2010$ the authors $\quad 0270-6474 / 10 / 3015686-09 \$ 15.00 / 0$
}

from an aged system, as the onset of most neurodegenerative diseases is during later life stages. It is therefore desirable to understand how the proliferative capacity of stem cells is altered with aging.

The epithelium of the VNO is an especially favorable system to investigate these issues. The VNO is a bilaterally symmetrical tubular structure located at the base of the septum containing a pseudostratified columnar epithelium composed of basal cells, intermediate neuronal precursors, mature sensory neurons, and sustentacular cells. The sensory neurons are CNS Golgi type I neurons with a long axon and glutamatergic synapses in the olfactory bulb (Firestein, 2001). The olfactory and vomeronasal epithelia are highly similar in the cell types represented (Mendoza, 1993). Basal cells are adult stem cells that retain the capacity to regenerate new neurons throughout life and are the primary cell type labeled by thymidine analogs (Schwartz Levey et al., 1991; Huard and Schwob, 1995; Halpern and Martínez-Marcos, 2003). The basal cell population gives rise to $\mathrm{MASH}^{+}{ }^{+}$progenitors and subsequently Neurogenin- ${ }^{+}$immediate neuronal precursors. In the VNO, precursors migrate both horizontally and vertically to become mature sensory neurons, which express both olfactory marker protein (OMP) and neural cell adhesion molecule (Calof et al., 2002; Halpern and Martínez-Marcos, 2003). Two types of stem cells have been indentified in the VNO. Cells found in the marginal zone are largely responsible for growth, whereas cells found in the central zone are associated with neuronal replacement (Weiler et al., 1999; Martínez-Marcos et al., 2000a,b; Weiler, 2005; De La Rosa-Prieto et al., 2009). We therefore sought to determine the capacity for neuronal growth and regeneration in the two stem cell populations in an aged environment. In particular, we asked whether and to what extent neuronal stem cells found in the aging vomeronasal system retain their capacity to regenerate in the face of diminishing tissue growth. 
A

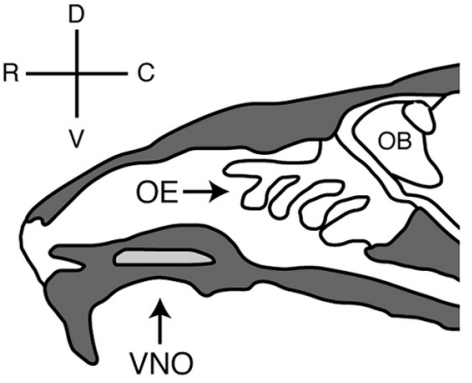

B BrdU
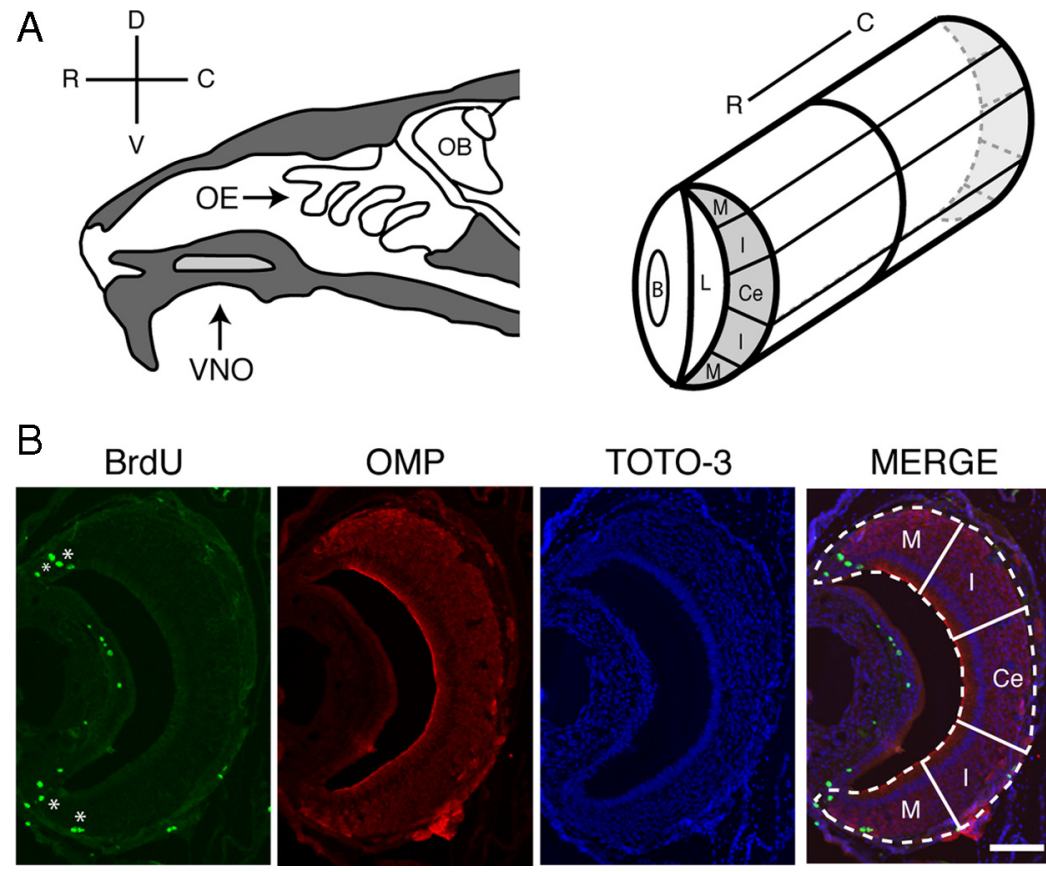

Figure 1. Organization and zones of the vomeronasal organ. $\boldsymbol{A}$, Schematics depicting the location of the VNO in the sagittal plane (left) and the coronal plane (right). The VNO is a bilaterally symmetrical tubular structure; shown here is one half of a coronal plane as it would appear through the depth of this structure. The marginal zones $(M)$ are found at the extreme dorsal $(D)$ and ventral (V) regions of the VN0. Adjacent to the marginal zones are the intermediate zones (I). In between the two intermediate zones is the central zone (Ce). Adapted with permission from Firestein, 2001 and Mombaerts, 2004. 0B, 0lfactory bulb; 0E, olfactory epithelium; $B$, blood vessel; $C$, caudal; $L$, lumen; $R$, rostral. $B$, Incorporation of BrdU (green) in the VN0 of a 2-month-old mouse is shown. TOTO-3 is a nuclear marker (blue) and OMP delineates the neuronal area of the VNO (red). Scale bar, $100 \mu \mathrm{m}$.

\section{Materials and Methods}

Animal care and sources. C57BL/6 mice, aged 1-24 months, were obtained from the National Institute on Aging Aged Rodent Colony. All experiments were performed in compliance with the Columbia University Institutional Animal Care and Use Committee.

Immunohistochemistry. Mice were anesthetized by intraperitoneal injection with a mixture of ketamine/xylazine $(18 \mathrm{mg} / \mathrm{ml}$ and $2 \mathrm{mg} / \mathrm{ml}$, respectively, in $0.05-0.15 \mathrm{ml}$ ) and perfused transcardially with heparinized (2-4 U/ml) PBS, pH 7.4, followed by 4\% paraformaldehyde (Electron Microscopy Sciences) in $0.1 \mathrm{~m}$ phosphate buffer (PB), pH 7.4. Vomeronasal epithelia were dissected, decalcified, cryoprotected $(30 \%$ sucrose), and frozen in OCT. Cryosections $(12 \mu \mathrm{m})$ were incubated in blocking solution containing $0.5 \%$ Triton X-100 and 5\% normal donkey serum in $0.1 \mathrm{M}$ PB for $1 \mathrm{~h}$ at room temperature. Primary antibody incubation was performed overnight at $4^{\circ} \mathrm{C}$ against OMP (goat polyclonal; 1:1500; Wako), 5-bromo-2'-deoxyuridine (BrdU; mouse monoclonal; 1:30; GE Healthcare Biosciences), and active caspase-3 (rabbit polyclonal; 1:200; Cell Signaling Technology). Sections were then incubated with Alexa Fluor 488and 594-conjugated secondary antibodies (1:750; Invitrogen) for $2 \mathrm{~h}$ at room temperature. TOTO-3 (1:10,000; Invitrogen) was added in a wash step after secondary incubation for visualization of nuclei. Sections were mounted in Vectashield (Vector Laboratories) to prevent photobleaching. Optical sections $(1 \mu \mathrm{m})$ were taken through the depth of the section with an Olympus FluoView 600 confocal microscope and analyzed with Image (NIH) software. Figures were assembled with Adobe Photoshop and Illustrator software.

Olfactory bulbectomy. Olfactory bulbectomy (OBX) was performed according to standard methods. Briefly, mice were anesthetized by intraperitoneal injection with a mixture of ketamine/xylazine $(18 \mathrm{mg} / \mathrm{ml}$ and $2 \mathrm{mg} / \mathrm{ml}$, respectively, in $0.05-0.15 \mathrm{ml}$ ). A small hole was cut in the frontal bone over the right olfactory bulb with a dental drill, and the bulb was removed by aspiration. The cavity was filled with Gelfoam (Pfizer Pharmacia and Upjohn) to control bleeding, and the skin over the wound was sutured closed with Vetbond (3M).
MERGE

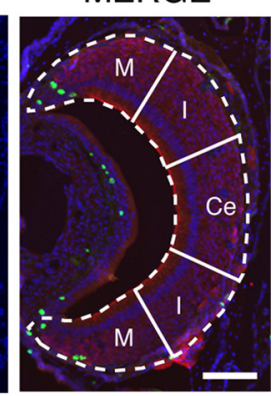

Proliferation assay. Proliferation was assessed by BrdU (Sigma) injection and was detected with an antibody recognizing $\mathrm{BrdU}$ (see above). For acute labeling experiments, 100 $\mathrm{mg} / \mathrm{kg}$ BrdU was injected $2 \mathrm{~h}$ before death. For maturation studies (see below), two injections $2 \mathrm{~h}$ apart of $50 \mathrm{mg} / \mathrm{kg}$ BrdU were given; the animals were then killed $30 \mathrm{~d}$ following injection. For olfactory bulbectomy studies, 100 $\mathrm{mg} / \mathrm{kg}$ was injected $2 \mathrm{~h}$ before death 5 or $30 \mathrm{~d}$ after OBX was performed.

Maturation assay. Cryosections were prepared as described above (see Immunohistochemistry, above). In all animals, at least 15 coronal sections throughout the VNO were examined to yield a minimum of 20 cells examined per animal. Optical sections $(1 \mu \mathrm{m})$ were taken with a $40 \times$ objective through the depth of the section with an Olympus FluoView 600 confocal microscope and analyzed with Image software. Complete overlap in all visual planes with a nuclear marker TOTO-3 was required to verify that examination was of a single BrdUlabeled cell. Z-projections through the middle of BrdU/TOTO-3-positive nuclei were then made to verify that OMP labeling surrounded the entire nucleus. Cells that exhibited partial labeling with OMP or those in which the plane of cryosection bisected the nucleus were not included in the analysis.

Stereology and quantification. Thin cryosections $(12 \mu \mathrm{m})$ were prepared as described above (see Immunohistochemistry, above). In all animals, every fifth section (60 $\mu \mathrm{m}$ increments) of vomeronasal epithelia was processed for BrdU and OMP immunohistochemistry, counted immediately with a Leica DMR microscope (Leica Microsystems) to minimize effects of photobleaching, and photographed with a SPOT digital camera (Diagnostic Instruments). Adjacent sections were processed for active caspase- 3 and OMP immunohistochemistry. The area of OMP immunoreactivity was used to define the reference space and was measured with ImageJ software to allow for normalization of counts. Counts were performed with the trained experimenter blind to condition in an unbiased, random manner with systematic sampling. Total number of BrdU-positive cells was not calculated but rather the number of BrdU-positive cells per unit area, as BrdU labeling observed at the dosages used herein is a rare event.

Reconstruction. The rostral and caudal extent of the VNO was determined in each animal. Cell counts were made for each position (see Stereology and quantification, above) and each position was normalized to the total length of the VNO, such that the rostral end of the epithelium corresponded to $0 \%$ and the caudal end to $100 \%$. For each $5 \%$ increment of VNO length, cell counts were pooled and averaged for each animal, as more than one section was counted for the range of each $5 \%$ increment. For each age group, cell counts were again averaged across all animals in that age group according to $5 \%$ increments in position. Finally, as absolute cell numbers labeled by BrdU decline with age in the marginal zone, for each position the percentage contribution to the total BrdU-positive cell count along the length of the VNO was determined. Data were graphically represented as heat maps with MathWorks MatLab software.

Statistical analysis. All statistical analyses were performed with GraphPad Prism software (GraphPad Software). For analysis of basal proliferation levels, all data were analyzed for statistical significance by one-way ANOVA and Student Newman-Keuls (SNK) pairwise multiple comparison between age groups. Where raw data did not pass Bartlett's test for equal variances, data were log transformed and subsequently analyzed by ANOVA as stated above (all zones and marginal zone). For reconstruction studies, percentage contribution at a given position was analyzed for statistical significance with a two-way ANOVA for the effects of age and 
position, followed by Bonferroni post hoc tests for the effect of position in all age groups. For maturation studies, data were expressed as a ratio defined by the number of cells that were both OMP-positive and BrdU-positive divided by the number of BrdU-positive cells, regardless of OMP status. As maturation ratio data were not normally distributed, they were arcsin transformed and analyzed with a one-way ANOVA and SNK pairwise multiple comparison between age groups. For olfactory bulbectomy studies, lesion and nonlesion control measurements were performed in the same tissue section to control for effects of position. As variances between lesion and nonlesion controls were unequal in all age groups, raw data were normalized to lesion values and transformed with an arcsin transformation. Normalized data were analyzed with two-way repeatedmeasures ANOVA for the effects of age and lesion, followed by Bonferroni post hoc tests between lesion and nonlesion controls for each age group.

\section{Results}

To assess how proliferation is affected by age, we used BrdU as a marker of cell proliferation. BrdU is a thymidine analog that is incorporated into the DNA of proliferating cells during the S-phase of the cell cycle, and provides a reliable, quantifiable immunoreactive signal. We chose BrdU instead of other proliferative markers such as Ki-67 or proliferating cell nuclear antigen because they are not specific to the phase of the cell cycle, exhibit nonspecific persistence beyond proliferation, or are subject to variability with fixation (Ohta and Ichimura, 2000; Muskhelishvili et al., 2003; Taupin, 2007). We injected 100 $\mathrm{mg} / \mathrm{kg}$ BrdU $2 \mathrm{~h}$ before death in mice in nine age groups, ranging from 1 to 24 months of age. The C57BL/6 mouse lifespan ranges up to an extreme of $\sim 30$ months of age (Konen et al., 1973). A nonsaturating dose of BrdU was chosen to avoid experimental confounds of toxicity (Cameron and McKay, 2001; Taupin, 2007). In coronal sections, the VNO was subdivided into three zones, as follows: the marginal zone, the intermediate zone, and the central zone (Fig. 1A, right panel; $B$, merge) (Giacobini et al., 2000). Utilizing stereological quantification of cells incorporating BrdU, we observed that the majority of immunoreactivity was in the basal cell layer. In addition, a minor level of proliferation occurred in the sustentacular (or supporting) cell region, clearly recognizable due to the elongated nuclei of sustentacular cells relative to the compact circular nuclei of the neurons found along the periphery of the epithelium. Proliferation in the sustentacular layer remained constant throughout the life of the animal (data not shown; $p>0.05$ ). In all age groups, a large proportion of BrdU incorporation was in the marginal zone (Figs. $1 B ; 2 A, C$ ). When counts from the basal cell layer in all zones were considered together, we observed that proliferation

A

B

C
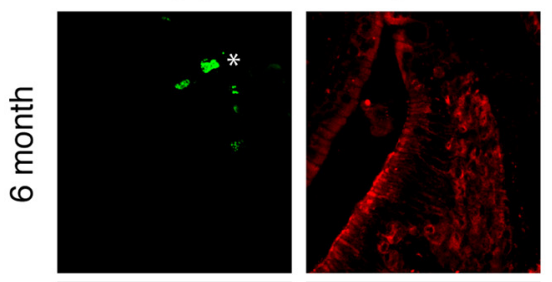

TOTO-3
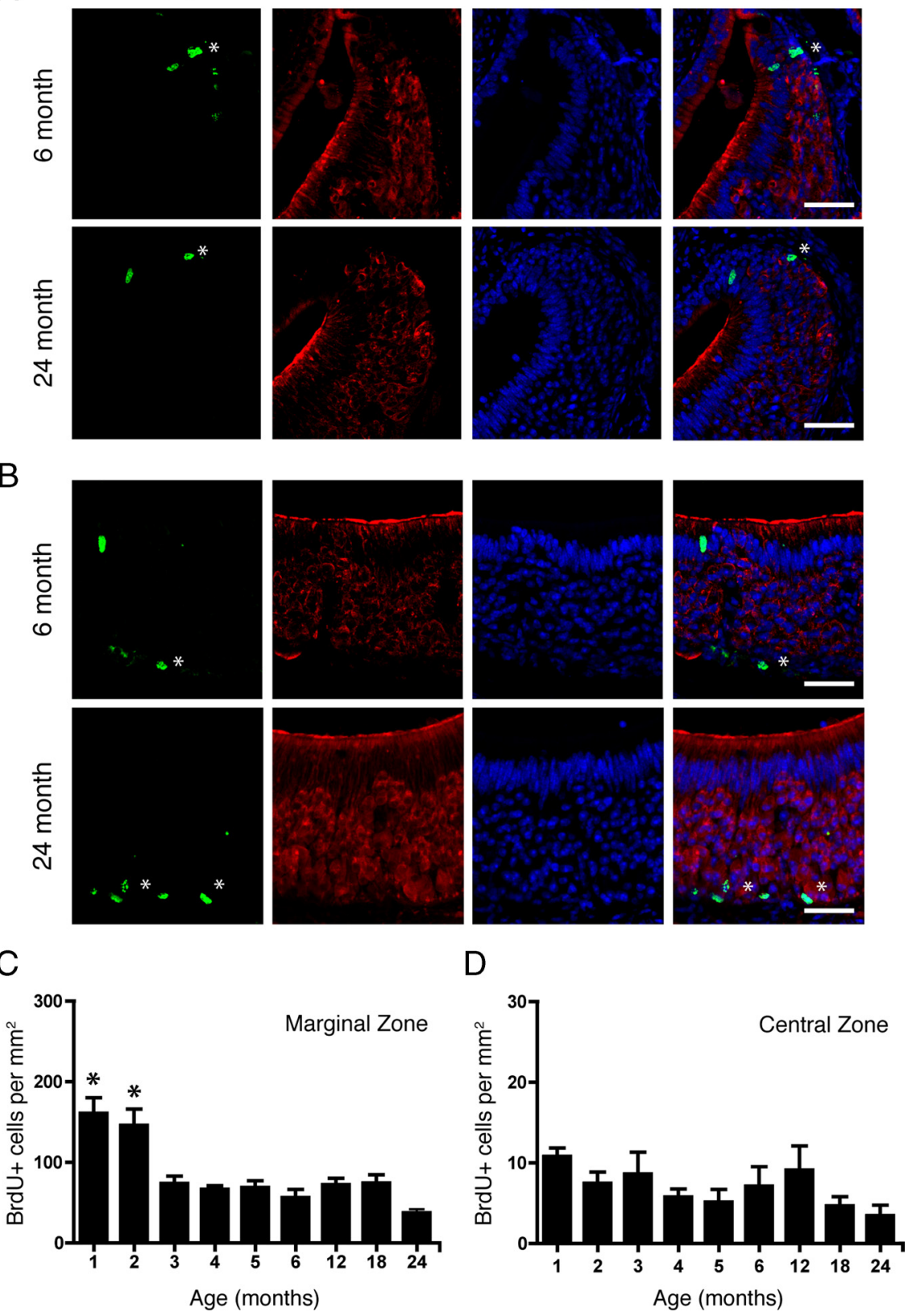

Figure 2. Proliferation decreases in the marginal zones but remains constant in the central zone of the VNO with age. $A$, Incorporation of BrdU (asterisks; green) in the marginal zone of the VNO of a 6-month-old (top) and a 24-month-old (bottom) mouse is shown in the merge of TOTO-3 (nuclear marker; blue) and OMP (red). $\boldsymbol{B}$, Same as in $\boldsymbol{A}$ but in the central zone of the VNO. C, Quantification of BrdU-positive cells per square millimeter in the marginal zone. ${ }^{*} p \leq 0.0001$. D, Quantification of BrdU-positive cells per square millimeter in the central zone. All data were analyzed for statistical significance by one-way ANOVA and SNK pairwise multiple comparison between age groups. $n=5-8$ animals per group. Scale bar, $50 \mu \mathrm{m}$.

decreases sharply following 2 months of age, and plateaus from 3 to 24 months of age (one-way ANOVA, $p<0.0001$ ) (Table 1). When data were analyzed separately by zone, proliferation decreased sharply with age in the marginal (one-way ANOVA, $p<$ 0.0001) (Fig. 2A,C; Table 1) and intermediate (one-way ANOVA, $p<0.0002$ ) zones (Table 1). However, in the central zone, proliferation remained constant throughout life (one-way ANOVA, $p>0.05$ ) (Fig. $2 B, D$; Table 1). In tissue sections adjacent to those analyzed for BrdU immunoreactivity, cell death was also quantified. In both the marginal (Fig. 3B) and central (Fig. $3 C$ ) zones, the number of cells immunoreactive for active 
Table 1. Proliferation across all zones of the vomeronasal organ as it varies with age (BrdU ${ }^{+}$cells $\left./ \mathrm{mm}^{2}\right)$

\begin{tabular}{llllr}
\hline Age (months) & All zones $^{* \S}$ & \multicolumn{1}{l}{$\begin{array}{l}\text { Marginal } \\
\text { zone }\end{array}$} & \multicolumn{1}{l}{$\begin{array}{l}\text { Intermediate } \\
\text { zone }^{\dagger}\end{array}$} & Central zone \\
\hline $1(n=6)$ & $195.9 \pm 19.2$ & $160.7 \pm 19.3$ & $24.4 \pm 4.3$ & $10.8 \pm 1.1$ \\
$2(n=7)$ & $181.6 \pm 24.9$ & $145.9 \pm 20.2$ & $23.6 \pm 4.5$ & $7.5 \pm 1.4$ \\
$3(n=5)$ & $95.8 \pm 12.6$ & $74.0 \pm 9.0$ & $13.2 \pm 3.1$ & $8.6 \pm 2.7$ \\
$4(n=5)$ & $83.7 \pm 4.2$ & $66.6 \pm 4.6$ & $11.4 \pm 1.5$ & $5.8 \pm 1.0$ \\
$5(n=5)$ & $85.4 \pm 11.4$ & $68.8 \pm 8.3$ & $11.4 \pm 2.6$ & $5.2 \pm 1.6$ \\
$6(n=7)$ & $74.3 \pm 13.4$ & $56.6 \pm 9.9$ & $10.6 \pm 2.3$ & $7.1 \pm 2.4$ \\
$12(n=6)$ & $91.7 \pm 11.8$ & $72.3 \pm 8.2$ & $10.3 \pm 2.4$ & $9.1 \pm 3.0$ \\
$18(n=8)$ & $87.9 \pm 11.3$ & $74.3 \pm 10.2$ & $8.8 \pm 1.3$ & $4.7 \pm 1.1$ \\
$24(n=6)$ & $48.0 \pm 7.5$ & $37.7 \pm 4.7$ & $6.8 \pm 2.1$ & $3.5 \pm 1.3$ \\
\hline
\end{tabular}

Values are presented as mean \pm SEM. All data were analyzed for statistical significance by one-way ANOVA and SNK pairwise multiple comparison between age groups. ${ }^{*} p \leq 0.0001 ;{ }^{\dagger} p \leq 0.0002$.

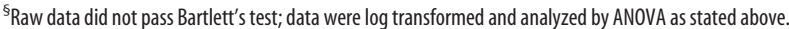

caspase-3 (aCasp3) (Fig. 3A) was not different across all age groups $(p>0.05)$. Interestingly, all aCasp 3 immunoreactivity observed was localized to the mature neuronal layer and not observed in the basal cell compartment.

We next calculated the ratio between proliferation (BrdUpositive cells) and death (active caspase-3-positive cells) in both the marginal and central zones for each animal in each age group. In young animals (1-2 months), the ratio was highest in the marginal zone, and this value was significantly different from that in the central zones. In adult and aged animals (6-24 months), the ratios in the two zones were not different (Fig. 3D). These data and the observed decline in growth-associated proliferation are consistent with the fact that horizontal migration from the marginal zones decreases by 2 months of age (Halpern and Martínez-Marcos, 2003) and is similar to the timing of the growth-associated decline observed in the olfactory epithelium (Hinds et al., 1984). The consistent level of cell death observed in all age groups further indicates the initial elevated amount of BrdU-incorporating cells in the marginal zone is due to growth during a restricted early postnatal period.
A
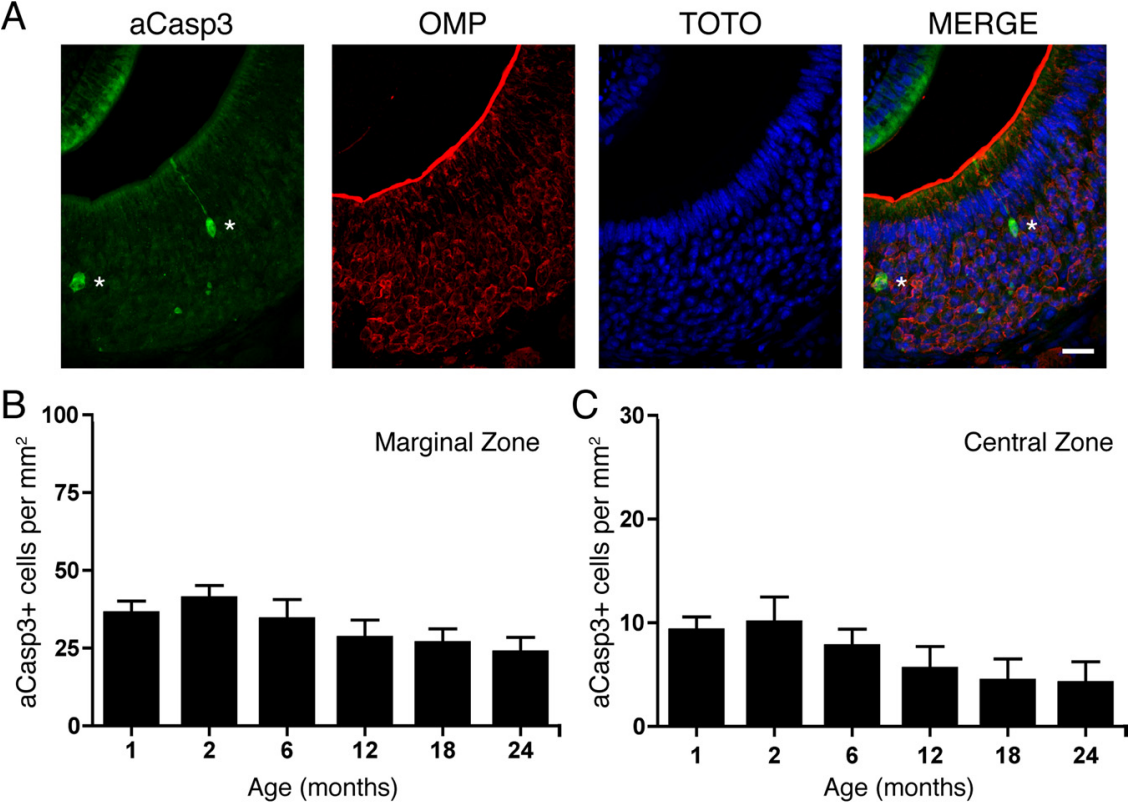

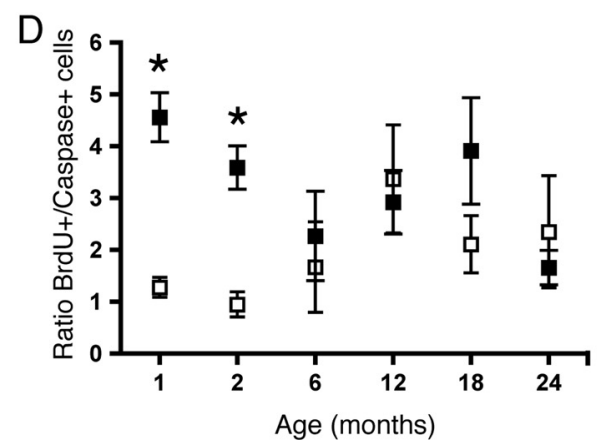

Figure 3. Cell death is constant in both the marginal and central zones of the VNO with age. $\boldsymbol{A}$, Two cells expressing aCasp3 (green), a marker of cell death, in the VNO of a 1-month-old mouse are marked with asterisks. Also shown is OMP (red), TOTO-3 (nuclear marker; blue), and the merge of the three images (right panel). Scale bar, $20 \mu \mathrm{m} . \boldsymbol{B}, \boldsymbol{C}$, Quantification of aCasp3-positive cells per square millimeter in the marginal $(\boldsymbol{B})$ and the central $(\boldsymbol{C})$ zones revealed no significant difference in the amount of cell death across all age groups. Data were analyzed for statistical significance by one-way ANOVA and SNK pairwise multiple comparison between age groups. $p>0.05 ; n=5-8$ animals per group. $\boldsymbol{D}$, The ratio of proliferating cells to dying cells in the marginal zone (filled squares) is significantly different (denoted by asterisks) from that in the central zone (open squares) in young mice (1 month, $p<0.001 ; 2$ month, $p<0.005$ ) but not in aged mice $(6-24$ months, $p>0.05)$. The ratio of BrdU-positive to active Caspase-3-positive cells was calculated for each animal in the marginal and central zones and analyzed for statistical significance by a paired Student's $t$ test. Other factors, such as the microenvironment that supports these progenitor cells, may cause the growth-associated decline in neurogenesis seen with age (Morrison and Spradling, 2008). Therefore, beyond the postnatal growth period, the level of constant proliferation and cell death observed in all age groups in the central zone likely results from vertical migration of new replacement neurons.

We next asked whether the distribution of BrdU incorporation throughout the rostral-caudal length of the VNO exhibited age-dependent changes. To do this, we reconstructed the pattern of labeling in the VNO following an acute 100 $\mathrm{mg} / \mathrm{kg}$ BrdU injection from mice aged from 1 to 24 months. Across all age groups and all zones of the epithelium, the majority of BrdU incorporation was at the most rostral and caudal extents of the VNO (Fig. 4). Hence, the number of cells incorporating BrdU is highest at the extremities of the VNO, regardless of zone, and this pattern does not change with age $(p>$ 0.05, two-way ANOVA for the effects of age and position).

As progenitor cells undergo proliferation, they generate more daughter cells than will mature into functional sensory neurons (Martínez-Marcos et al., 2005). It is not clear whether age affects the potential for newly generated cells to become functional neurons. To further probe this question, we injected mice, ranging in age from 1 to 24 months of age, with two doses of $50 \mathrm{mg} / \mathrm{kg}$ BrdU $2 \mathrm{~h}$ apart on $\mathrm{d} 0$. Mice were then killed $30 \mathrm{~d}$ following BrdU injection. Single cells (as verified by the nuclear marker, TOTO-3) incorporating BrdU were subsequently examined with confocal microscopy for colocalization of OMP, a marker of neuronal maturity (Fig. 
$5 B)$. No significant differences were observed between age groups ( $p>0.05$, oneway ANOVA), with approximately with one-third of the BrdU+ cells having become mature sensory neurons (Fig. 5A).

Since the proportion of mature sensory neurons does not decline with age, we next asked whether the regenerative capacity of this neural stem cell was retained in aged animals after injury. The regenerative capacity of both the olfactory epithelium and the vomeronasal epithelium of young animals has been studied extensively with several paradigms, including target ablation (unilateral olfactory bulbectomy), sensory deprivation (unilateral naris occlusion), axotomy, and chemical ablation of the epithelium (for review, see Halpern and Martínez-Marcos, 2003). Lesion of the axons extending from the olfactory epithelium and VNO to the olfactory bulb by OBX results in a wave of apoptotic cell death that selectively targets all neurons in the epithelium within $5 \mathrm{~d}$ of the lesion. However, the robust regenerative capacity of the basal cells repopulates the epithelia with $>8-10$ million new neurons within 3-4 weeks (Costanzo and Graziadei, 1983; Schwartz Levey et al., 1991; Caggiano et al., 1994; Kastner et al., 2000; YoshidaMatsuoka et al., 2000; Matsuoka et al., 2001, 2002; Carter et al., 2004).

Since previous lesion experiments were conducted in young animals, we asked whether this remarkable regenerative capacity in response to injury is lost with age. We first performed unilateral OBX in mice aged 2, 6, and 24 months. Five days after surgery, mice were injected with $100 \mathrm{mg} / \mathrm{kg}$ BrdU $2 \mathrm{~h}$ before death and their vomeronasal epithelia were examined for BrdU incorporation. In all age groups, we observed that proliferation in the basal cell compartment increased following lesion throughout all areas of the VNO (Fig. 6C,D) over that of the nonlesioned controls (Fig. $6 A, B$ ). Following stereological quantification, we observed that proliferation significantly increased in all zones in all age groups after OBX over the nonlesioned controls VNO ( $p<0.01$ for the effect of surgery, $p>0.05$ for the effect of age, two-way repeated-measures ANOVA for the effects of age and surgery) (Fig. $7 A-C$ ). These data demonstrate that, although the normal pace of proliferation slows over age, the capacity for robust proliferation remains latent and unchanged when challenged.

The olfactory bulbectomy lesion model requires the removal of the olfactory bulb and thus the target for the regrowing neurons is absent. In younger animals, this sustained lesion results in the continuous turnover of sensory neurons as the newly generated cells fail to find a target and die. We were therefore interested in these continuing effects in the aged epithelium. To test this, we again performed unilateral OBX in mice aged 1, 2, 6, 12, and 18 months. We then waited $30 \mathrm{~d}$ postsurgery before injecting mice with $100 \mathrm{mg} / \mathrm{kg}$ BrdU before death. In both young ( 2 month) and aged (18 month) mice, proliferation was increased throughout the lesioned VNO (Fig. 6G,H) over that of nonlesion controls
(Fig. 6E,F). When data were analyzed by zone, a significant increase in proliferation following lesion was observed in all zones of the VNO and in all age groups $(p<0.0001$ for the effect of surgery; $p>0.05$ for the effect of age, two-way repeatedmeasures ANOVA for the effects of age and surgery) (Fig. 7D-F). These data show that the capacity for long-term neuronal regeneration from adult stem cells is undiminished even in very old animals.

\section{Discussion}

Regeneration and proliferation of neurons in adults and particularly aged organisms could have significant clinical implications for restoring brain function due to injury or pathology. Although the young brain has limited regenerative capacity, it has been thought that in the aged brain this capacity is further diminished. We have shown here that, among a population of excitatory projection neurons, this is not the case.

The phenomenon of neurogenesis has been most commonly investigated with thymidine analogues such as BrdU to label proliferative cell populations. The loss of BrdU immunoreactivity following high doses of irradiation (Taupin, 2007; Valley et al., 2009) suggests that BrdU incorporation does not typically reflect DNA repair. In addition, a study examining the specificity of BrdU incorporation following three well characterized models of injury (irradiation, olfactory bulbectomy, and kainic acid- 


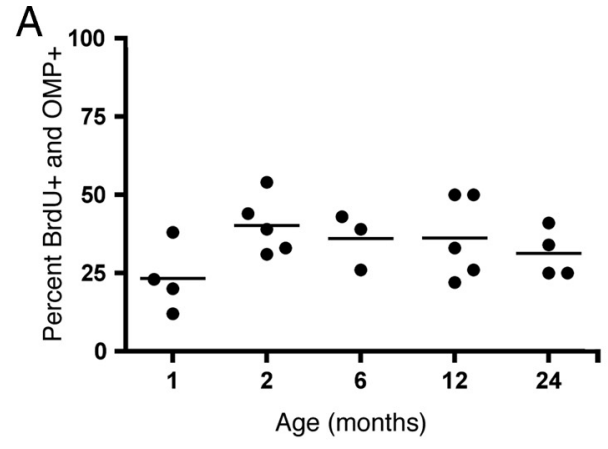

B
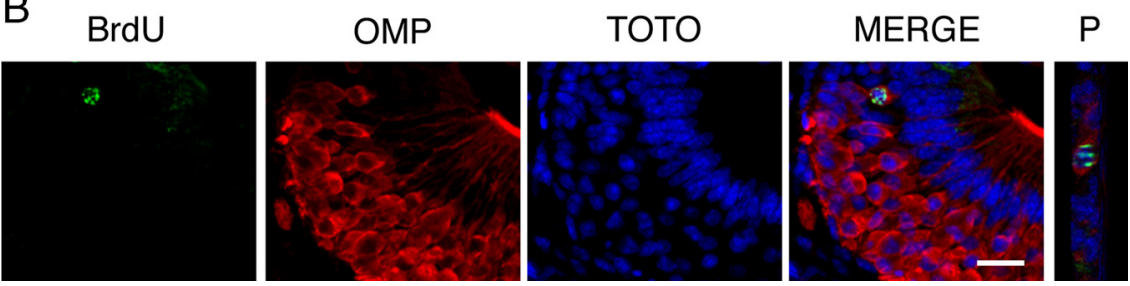

Figure 5. Cells incorporating BrdU become mature sensory neurons at the same rate in both young and aged VN0. Mice were injected twice with $50 \mathrm{mg} / \mathrm{kg}$ BrdU $2 \mathrm{~h}$ apart, killed $30 \mathrm{~d}$ following injection, and cells incorporating BrdU were analyzed for the coexpression of OMP, a marker of vomeronasal sensory neuron maturity. $\boldsymbol{A}$, The percentage of cells incorporating BrdU that reach maturity (OMP-positive) is consistent across all age groups tested (1, 2, 6, 12, and 24 months of age; one-way ANOVA, $n=3-5$ animals per group, $p>0.05$ ). A horizontal line represents the mean for each group. $\boldsymbol{B}$, Representative confocal images of a BrdU-positive cell (green) surrounded by 0MP (red). Z-projections of all BrdU-immunoreactive cells were made (projection, P) and examined for overlap with OMP and TOTO-3 (blue, nuclei) to verify that OMP immunoreactivity surrounded a single BrdU-positive nucleus. Scale bar, $20 \mu \mathrm{m}$.
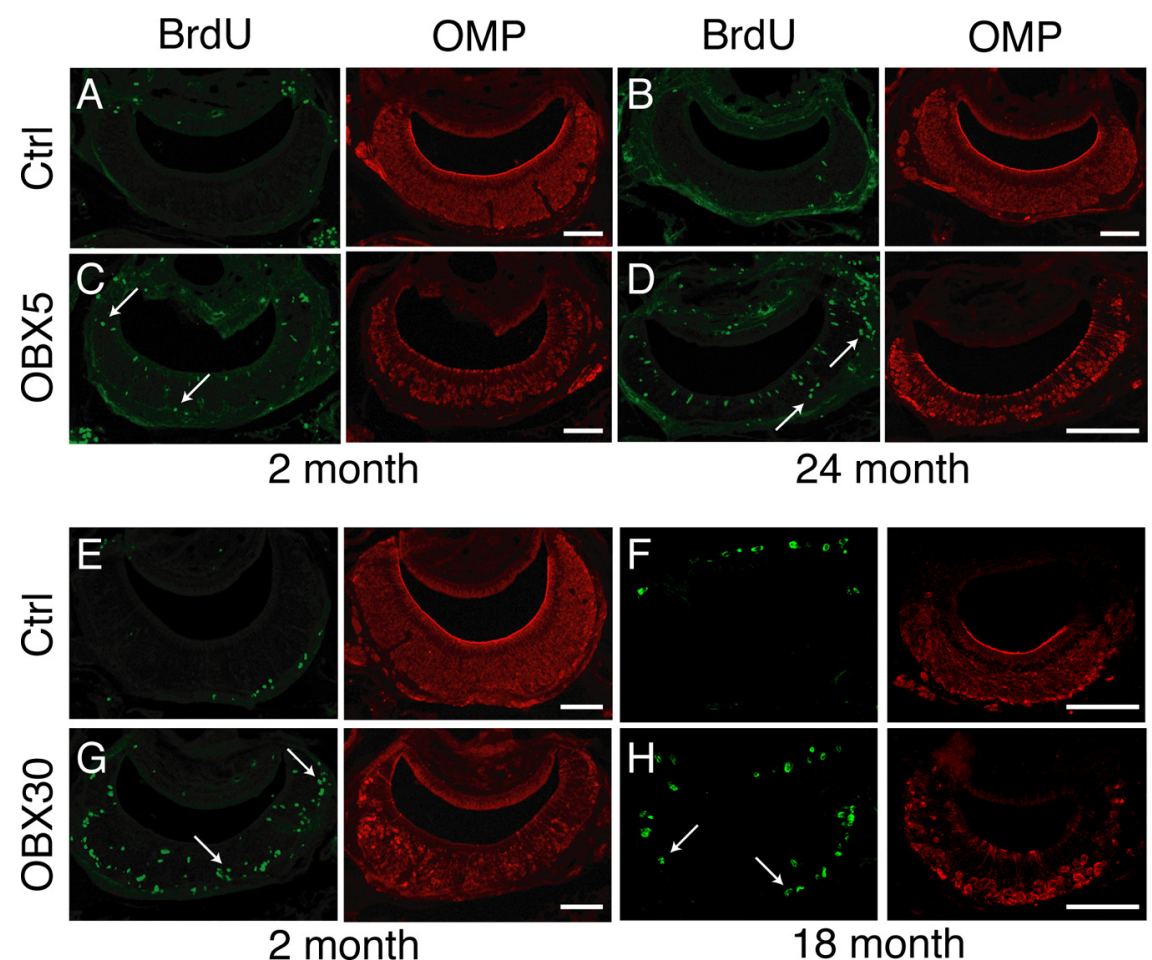

Figure 6. Acute and sustained unilateral OBX lesion induces increased proliferation in the VNO in young and aged mice. BrdU was administered $2 \mathrm{~h}$ before death on $\mathrm{d} 5(\mathrm{OBX} 5 ; \boldsymbol{A}-\boldsymbol{D})$ or d $30(0 \mathrm{BX} 30 ; \boldsymbol{E}-\boldsymbol{H})$ following OBX. $\boldsymbol{A}, \mathrm{BrdU}$ (green) and OMP (red) in nonlesioned control (Ctrl) 2-month-old VNO. B, As in $\boldsymbol{A}$ but for control 24-month-old VNO. C, BrdU and OMP in lesioned (OBX5) 2-month-old VNO. D, As in C but for lesioned 24-month-old VNO. $\boldsymbol{E}$, BrdU and OMP in nonlesioned control 2-month-old VNO. $\boldsymbol{F}$, As in $\boldsymbol{E}$ but for control 18-month-old VN0. G, BrdU and OMP in lesioned 2-month-old VN0. $\boldsymbol{H}$, As in $\boldsymbol{G}$ but for lesioned (0BX30) 18-month-old VNO. Note the increase in BrdU incorporation throughout all zones of the VNO (arrows) in all age groups. Scale bars, $100 \mu \mathrm{m}$. induced seizure) provides additional evidence that $\mathrm{BrdU}$ is not significantly incorporated during DNA repair. BrdU incorporation occurred principally in cells undergoing DNA synthesis. In particular, in the olfactory epithelium following olfactory bulbectomy in young adult animals, dying cells were positive for TUNEL (Tdtmediated dUTP-biotin nick end labeling), a cell death marker, but rarely incorporated BrdU (Bauer and Patterson, 2005). These data suggest that postmitotic dying neurons do not reenter the cell cycle following lesion and that BrdU administration is an appropriate experimental approach to monitor proliferation in the olfactory system.

A decline in neurogenesis with normal aging has been observed in the rare populations of adult neurogenic cells in the nervous system. In the CNS, the agerelated decline in neurogenesis has been demonstrated in the subgranular zone (SGZ) that supplies new neurons to the dentate gyrus of the hippocampus (Rao et al., 2006) and the subventricular zone (SVZ) that supplies new neurons to the olfactory bulb (Ahlenius et al., 2009). The observed decline is due to a loss of progenitor populations in the SGZ (Olariu et al., 2007) but neurons generated from these remaining progenitors exhibit normal spine density in mice up to 10 months of age (Morgenstern et al., 2008). Although maturation of progenitors derived from the SGZ was retarded, the migration, survival, and neuronal fate choice was normal in the aged rat (Rao et al., 2005). A similar result was observed in the SVZ, where the numbers (Luo et al., 2006) and potential of neuronal stem cells were diminished in aged mice (Maslov et al., 2004).

In the olfactory epithelium, several studies have demonstrated that neurogenesis continues into adulthood (Farbman, 1990; Mackay-Sim and Kittel, 1991; Fung et al., 1997). In general, although these studies do not examine neurogenesis in aged animals, a decline in the rate of neurogenesis has been observed with increasing postnatal age. For example, proliferation was examined up to 3 months of age in mice (MackaySim and Kittel, 1991), and 11 months of age in rats (Weiler and Farbman, 1997, 1998). In addition, age affects the expression of regulators of the cell cycle in the olfactory epithelium (8.5-month-old mice) (Legrier et al., 2001). Similar to our findings in the mouse VNO, proliferation in the guinea pig olfactory epithelium was decreased by 4 months of age and was maintained at a constant level from 4 to 
A

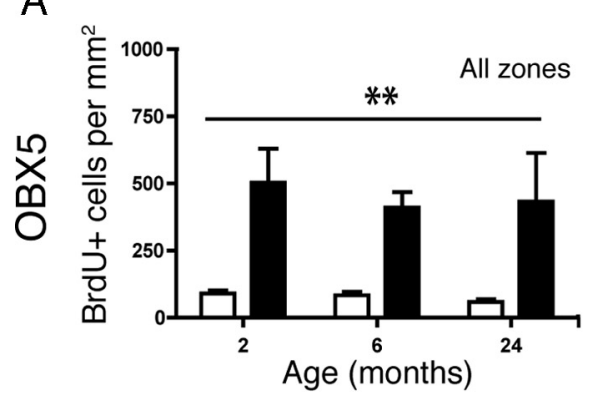

$\mathrm{D}$

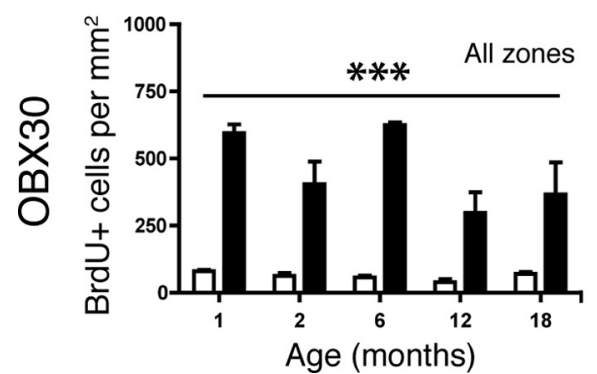

$\mathrm{B}$

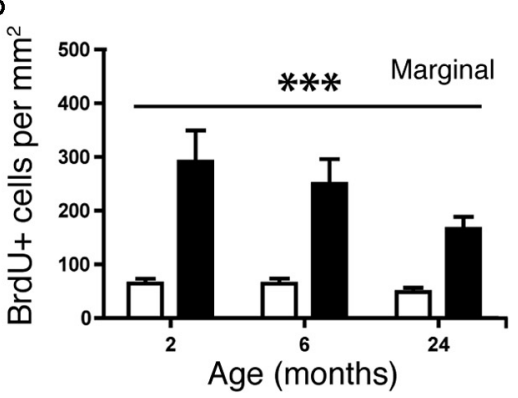

$E$

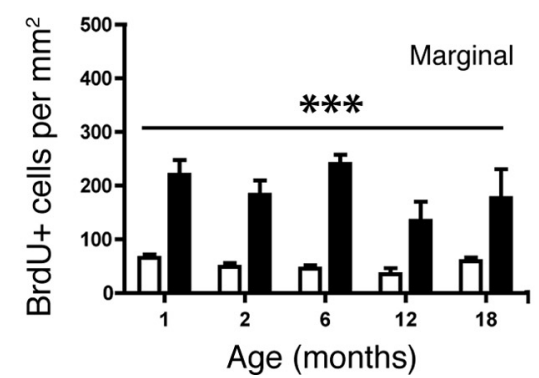

C

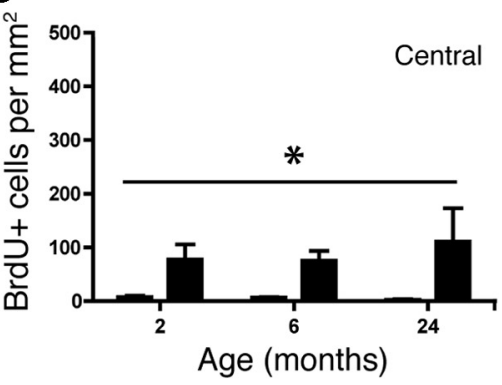

$\mathrm{F}$

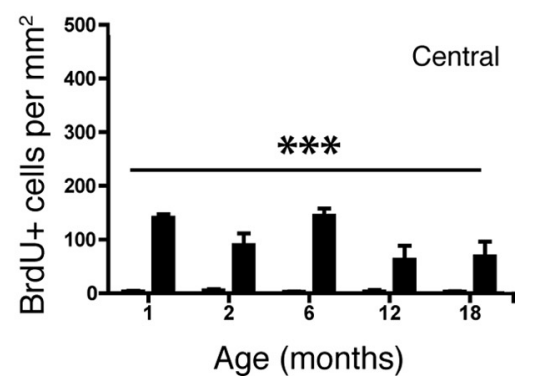

Figure 7. Acute and sustained unilateral OBX lesion induces increased proliferation in all zones of the VNO in young and aged mice. $\boldsymbol{A}-\boldsymbol{F}, \mathrm{BrdU}$ was administered $2 \mathrm{~h}$ before death on $\mathrm{d} 5(\mathrm{OBX} 5$; $A-C)$ and d $30(0 B X 30 ; D-F)$ following OBX. A-C, Quantification of BrdU incorporation reveals a significant increase in proliferation in the VNO following acute $0 B X$ (black bars) over that in the nonlesion control (white bars) in all zones $\left(\boldsymbol{A},{ }^{* *} p<0.003\right)$, marginal zone $\left(\boldsymbol{B},{ }^{* * *} p<0.0003\right)$, and central zone $\left(\boldsymbol{C},{ }^{*} p<0.01\right)$, regardless of age $(n=3$ per group). $\boldsymbol{D}-\boldsymbol{F}$, Quantification of BrdU incorporation reveals a significant increase in proliferation in the VNO following sustained OBX (black bars) over that in the nonlesion control (white bars) in all zones $(\boldsymbol{D})$, marginal zone $(\boldsymbol{E})$ and central zone $\left.(\boldsymbol{F}){ }^{* * *} p<0.0001\right)$ regardless of age $(n=3-7$ per group). All data were analyzed by two-way repeated-measures ANOVA for the effects of surgery ( $p$ values noted above) and age (not significantly different).

24 months. Interestingly, proliferation levels dropped after 24 months of age (Nakamura et al., 1998). However, this report only examined the guinea pig up to 36 months of age and the lifespan of this rodent ranges up to 72 months of age. Additionally, it is difficult to separate the difference between growth and cell replacement in the olfactory epithelium.

In the accessory olfactory system, including the VNO, there is a lack of data regarding the effects of aging on its regenerative capacity. The presence of proliferative cells in the normal snake (Holtzman, 1998), mouse (Martínez-Marcos et al., 2005), and lesioned mouse (Wakabayashi and Ichikawa, 2007) VNO is established, but the rodent studies use young (2-5-month-old) adult animals and therefore do not query age as a specific variable. A report in rat VNO presents evidence of declining proliferation with age, but its oldest group was 24 months of age in a rodent with a typical lifespan of 36 months, and it did not assess the response to injury (Weiler et al., 1999).

The response to injury of aged neuronal tissue is of intense interest for both basic research and clinical intervention. The brain is particularly sensitive to damage at advanced ages following injury, such as ischemia, and it is not understood why this is the case, nor how to alleviate this sensitivity (Popa-Wagner et al., 2009). One possible solution is that the regenerative potential of neuronal stem cells may be exploited to repair damage inflicted by injury. However, to date, variable results have been observed following injury in the neurogenic regions of the nervous system. Stroke resulted in an increase in new neurons in the striatum, but not in the subgranular zone (Darsalia et al., 2005). In the SVZ, the intrinsic differentiation potential of neuronal stem cells in young adult rats was not altered following stroke; however, the response of aged adults was not examined (Liu et al., 2009). A postmortem analysis of aged human SVZ indicated that neuronal progenitors increase following ischemia, but it is difficult to assess cell dynamics or neuronal maturation in postmortem brain tissue (Macas et al., 2006). Our finding that an easily accessible neuronal stem cell population is able to robustly respond to a severe injury paradigm is in contrast to recent work in the hippocampus that has demonstrated that aged neuronal stem cells in the SGZ do not retain their capacity for neurogenesis following deafferentation by kainic acid (Shetty et al., 2010). However, we cannot draw conclusions about whether neurons born in response to injury in aged animals are able to extend their axons to the accessory olfactory bulb, as the lesion method requires removal of the target of these axons. However, newly generated neurons in very old animals do reach maturity, as shown by expression of the marker OMP.

Several lesion models have been used to probe the proliferative capacity of olfactory and vomeronasal epithelia. In the olfactory epithelium, 6-month-old mice were able to recover function following zinc sulfate lesion, which disrupts the structure of the epithelium, indicating that the neural stem cells were able to successfully reconstitute the tissue at this young adult stage (Ducray et al., 2002). Here, we performed olfactory bulbectomy, a lesion that severs the axons of the vomeronasal and olfactory sensory neurons and induces programmed cell death specifically in the sensory neuron population (Schwartz Levey et al., 1991; Carr and Farbman, 1992). Within a day of lesion, macrophages were recruited to remove dying cell debris (Suzuki et al., 1995). Macrophages secrete leukemia inhibitory factor, which causes an increase in basal cell proliferation (Nan et al., 2001; Getchell et al., 2002). At the same time, loss of sensory neurons results in the decrease of growth and differentiation factor 11 (GDF11), a member of the TGF $\beta$ superfamily and secreted negative regulator of neurogenesis (Wu et al., 2003). GDF11 likely controls the rep- 
lication probability of immediate neuronal precursors (Lander et al., 2009). These factors, in concert with other secreted factors and cell cycle proteins, induce proliferation and cell maturation to result in the rapid repopulation (within $10 \mathrm{~d}$ ) of the epithelia with new sensory neurons (Kastner et al., 2000). To the best of our knowledge, the expression of GDF11 has not been examined in aged mice. However, it is likely that it is acting similarly in the aged epithelium; normally, neurogenesis is kept at a low level, but is permitted to increase when needed to mount an injury response.

It has been suggested that the exposure of sensory neurons to environmental damage may require their regular replacement (Gaskell, 1990; Dahl and Lewis, 1993; Upadhyay and Holbrook, 2004; Yankner et al., 2008). However, we find here that stem cells of the more protected vomeronasal epithelium undergo regular neuronal proliferation, maturation, and cell death as is observed in the more exposed olfactory epithelium. Additionally, we and others have noted the difference between growth and replacement of damaged neurons, and this replacement is a very slow process under normal conditions. Nonetheless, the proliferative capacity in response to damage remains robust even with advanced age. Furthermore, the response to injury can be sustained; in the absence of a target tissue, the subsequent death of maturing neurons appears to provide a signal to the stem cells that proliferation should continue at a high rate. Similarly, a recent descriptive report of nestin expression in human olfactory epithelium of aged individuals exhibiting hyposmia and/or anosmia suggests that aged humans may also retain the regenerative capacity described here (Minovi et al., 2010). The search for the signal, or signals, involved in the reconstitution of the olfactory epithelia must now be expanded to include aged animals. Interestingly, p53, a gene best known for its role in tumor suppression, controls the regenerative capacity of neuronal precursors in the subventricular zone (Medrano et al., 2009). It is possible that the mechanism governing proliferation of neuronal stem cells in the peripheral olfactory system includes p53 or its family members.

Although the remarkable proliferative capacity of the olfactory system has been known for some three decades, the regulatory mechanisms, and indeed the functional purpose, have remained obscure. The studies described here extend this robust and nearly unique phenomenon to a population of very old animals. The potential for neuronal replacement through an adult stem cell population is now also extended into an aging neuronal population.

\section{References}

Ahlenius H, Visan V, Kokaia M, Lindvall O, Kokaia Z (2009) Neural stem and progenitor cells retain their potential for proliferation and differentiation into functional neurons despite lower number in aged brain. J Neurosci 29:4408-4419.

Bailey KJ, Maslov AY, Pruitt SC (2004) Accumulation of mutations and somatic selection in aging neural stem/progenitor cells. Aging Cell 3:391-397.

Bauer S, Patterson PH (2005) The cell cycle-apoptosis connection revisited in the adult brain. J Cell Biol 171:641-650.

Caggiano M, Kauer JS, Hunter DD (1994) Globose basal cells are neuronal progenitors in the olfactory epithelium: a lineage analysis using a replication-incompetent retrovirus. Neuron 13:339-352.

Calof AL, Bonnin A, Crocker C, Kawauchi S, Murray RC, Shou J, Wu HH (2002) Progenitor cells of the olfactory receptor neuron lineage. Microsc Res Tech 58:176-188.

Cameron HA, McKay RD (2001) Adult neurogenesis produces a large pool of new granule cells in the dentate gyrus. J Comp Neurol 435:406-417.

Carr VM, Farbman AI (1992) Ablation of the olfactory bulb up-regulates the rate of neurogenesis and induces precocious cell death in olfactory epithelium. Exp Neurol 115:55-59.
Carter LA, MacDonald JL, Roskams AJ (2004) Olfactory horizontal basal cells demonstrate a conserved multipotent progenitor phenotype. J Neurosci 24:5670-5683.

Costanzo RM, Graziadei PP (1983) A quantitative analysis of changes in the olfactory epithelium following bulbectomy in hamster. J Comp Neurol 215:370-381.

Dahl AR, Lewis JL (1993) Respiratory tract uptake of inhalants and metabolism of xenobiotics. Annu Rev Pharmacol Toxicol 33:383-407.

Darsalia V, Heldmann U, Lindvall O, Kokaia Z (2005) Stroke-induced neurogenesis in aged brain. Stroke 36:1790-1795.

De La Rosa-Prieto C, Saiz-Sanchez D, Ubeda-Bañon I, Argandoña-Palacios L, Garcia-Muñozguren S, Martinez-Marcos A (2009) Fate of marginal neuroblasts in the vomeronasal epithelium of adult mice. J Comp Neurol 517:723-736.

Ducray A, Bondier JR, Michel G, Bon K, Millot JL, Propper A, Kastner A (2002) Recovery following peripheral destruction of olfactory neurons in young and adult mice. Eur J Neurosci 15:1907-1917.

Farbman AI (1990) Olfactory neurogenesis: genetic or environmental controls? Trends Neurosci 13:362-365.

Firestein S (2001) How the olfactory system makes sense of scents. Nature 413:211-218.

Fung KM, Peringa J, Venkatachalam S, Lee VM, Trojanowski JQ (1997) Coordinate reduction in cell proliferation and cell death in mouse olfactory epithelium from birth to maturity. Brain Res 761:347-351.

Gaskell BA (1990) Nonneoplastic changes in the olfactory epithelium: experimental studies. Environ Health Perspect 85:275-289.

Getchell TV, Shah DS, Partin JV, Subhedar NK, Getchell ML (2002) Leukemia inhibitory factor mRNA expression is upregulated in macrophages and olfactory receptor neurons after target ablation. J Neurosci Res 67:246-254.

Giacobini P, Benedetto A, Tirindelli R, Fasolo A (2000) Proliferation and migration of receptor neurons in the vomeronasal organ of the adult mouse. Brain Res Dev Brain Res 123:33-40.

Graziadei PP, Monti Graziadei AG (1983) Regeneration in the olfactory system of vertebrates. Am J Otolaryngol 4:228-233.

Halpern M, Martínez-Marcos A (2003) Structure and function of the vomeronasal system: an update. Prog Neurobiol 70:245-318.

Hinds JW, Hinds PL, McNelly NA (1984) An autoradiographic study of the mouse olfactory epithelium: evidence for long-lived receptors. Anat Rec 210:375-383.

Holtzman DA (1998) Cell dynamics in the embryonic and postnatal vomeronasal epithelium of snakes. Microsc Res Tech 41:471-482.

Huard JM, Schwob JE (1995) Cell cycle of globose basal cells in rat olfactory epithelium. Dev Dyn 203:17-26.

Kastner A, Moyse E, Bauer S, Jourdan F, Brun G (2000) Unusual regulation of cyclin D1 and cyclin-dependent kinases cdk2 and cdk4 during in vivo mitotic stimulation of olfactory neuron progenitors in adult mouse. J Neurochem 74:2343-2349.

Konen TG, Smith GS, Walford RL (1973) Decline in mixed lymphocyte reactivity of spleen cells from aged mice of a long-lived strain. J Immunol 110:1216-1221.

Lander AD, Gokoffski KK, Wan FY, Nie Q, Calof AL (2009) Cell lineages and the logic of proliferative control. PLoS Biol 7:e15.

Legrier ME, Ducray A, Propper A, Chao M, Kastner A (2001) Cell cycle regulation during mouse olfactory neurogenesis. Cell Growth Differ 12:591-601.

Liu F, You Y, Li X, Ma T, Nie Y, Wei B, Li T, Lin H, Yang Z (2009) Brain injury does not alter the intrinsic differentiation potential of adult neuroblasts. J Neurosci 29:5075-5087.

Luo J, Daniels SB, Lennington JB, Notti RQ, Conover JC (2006) The aging neurogenic subventricular zone. Aging Cell 5:139-152.

Macas J, Nern C, Plate KH, Momma S (2006) Increased generation of neuronal progenitors after ischemic injury in the aged adult human forebrain. J Neurosci 26:13114-13119.

Mackay-Sim A, Kittel P (1991) Cell dynamics in the adult mouse olfactory epithelium: a quantitative autoradiographic study. J Neurosci 11:979-984.

Martínez-Marcos A, Ubeda-Bañón I, Halpern M (2000a) Cell turnover in the vomeronasal epithelium: evidence for differential migration and maturation of subclasses of vomeronasal neurons in the adult opossum. J Neurobiol 43:50-63.

Martínez-Marcos A, Ubeda-Bañón I, Deng L, Halpern M (2000b) Neuro- 
genesis in the vomeronasal epithelium of adult rats: evidence for different mechanisms for growth and neuronal turnover. J Neurobiol 44:423-435.

Martínez-Marcos A, Jia C, Quan W, Halpern M (2005) Neurogenesis, migration, and apoptosis in the vomeronasal epithelium of adult mice. J Neurobiol 63:173-187.

Maslov AY, Barone TA, Plunkett RJ, Pruitt SC (2004) Neural stem cell detection, characterization, and age-related changes in the subventricular zone of mice. J Neurosci 24:1726-1733.

Matsuoka M, Yoshida-Matsuoka J, Iwasaki N, Norita M, Costanzo RM, Ichikawa M (2001) Immunocytochemical study of G(i)2alpha and $\mathrm{G}(\mathrm{o})$ alpha on the epithelium surface of the rat vomeronasal organ. Chem Senses 26:161-166.

Matsuoka M, Osada T, Yoshida-Matsuoka J, Ikai A, Ichikawa M, Norita M, Costanzo RM (2002) A comparative immunocytochemical study of development and regeneration of chemosensory neurons in the rat vomeronasal system. Brain Res 946:52-63.

Medrano S, Burns-Cusato M, Atienza MB, Rahimi D, Scrable H (2009) Regenerative capacity of neural precursors in the adult mammalian brain is under the control of p53. Neurobiol Aging 30:483-497.

Mendoza AS (1993) Morphological studies on the rodent main and accessory olfactory systems: the regio olfactoria and vomeronasal organ. Ann Anat 175:425-446.

Mimeault M, Batra SK (2009) Recent insights into the molecular mechanisms involved in aging and the malignant transformation of adult stem/ progenitor cells and their therapeutic implications. Ageing Res Rev $8: 94-112$

Minovi A, Witt M, Prescher A, Gudziol V, Dazert S, Hatt H, Benecke H (2010) Expression and distribution of the intermediate filament protein nestin and other stem cell related molecules in the human olfactory epithelium. Histol Histopathol 25:177-187.

Mombaerts P (2004) Genes and ligands for odorant, vomeronasal and taste receptors. Nat Rev Neurosci 5:263-278.

Morgenstern NA, Lombardi G, Schinder AF (2008) Newborn granule cells in the ageing dentate gyrus. J Physiol 586:3751-3757.

Morrison SJ, Spradling AC (2008) Stem cells and niches: mechanisms that promote stem cell maintenance throughout life. Cell 132:598-611.

Muskhelishvili L, Latendresse JR, Kodell RL, Henderson EB (2003) Evaluation of cell proliferation in rat tissues with BrdU, PCNA, Ki-67(MIB-5) immunohistochemistry and in situ hybridization for histone mRNA. J Histochem Cytochem 51:1681-1688.

Nakamura H, Fujiwara M, Kawasaki M, Nonomura N, Takahashi S (1998) Age-related changes in dividing cells of the olfactory epithelium of the maturing guinea pig. Eur Arch Otorhinolaryngol 255:289-292.

Nan B, Getchell ML, Partin JV, Getchell TV (2001) Leukemia inhibitory factor, interleukin-6, and their receptors are expressed transiently in the olfactory mucosa after target ablation. J Comp Neurol 435:60-77.

Ohta Y, Ichimura K (2000) Proliferation markers, proliferating cell nuclear antigen, Ki67, 5-bromo-2'-deoxyuridine, and cyclin D1 in mouse olfactory epithelium. Ann Otol Rhinol Laryngol 109:1046-1048.

Olariu A, Cleaver KM, Cameron HA (2007) Decreased neurogenesis in aged rats results from loss of granule cell precursors without lengthening of the cell cycle. J Comp Neurol 501:659-667.
Popa-Wagner A, Buga AM, Kokaia Z (2009) Perturbed cellular response to brain injury during aging. Ageing Res Rev. Advance online publication. Retrieved April 6, 2010. doi:10.1016/j.arr.2009.10.008.

Rao MS, Hattiangady B, Abdel-Rahman A, Stanley DP, Shetty AK (2005) Newly born cells in the ageing dentate gyrus display normal migration, survival and neuronal fate choice but endure retarded early maturation. Eur J Neurosci 21:464-476.

Rao MS, Hattiangady B, Shetty AK (2006) The window and mechanisms of major age-related decline in the production of new neurons within the dentate gyrus of the hippocampus. Aging Cell 5:545-558.

Schwartz Levey M, Chikaraishi DM, Kauer JS (1991) Characterization of potential precursor populations in the mouse olfactory epithelium using immunocytochemistry and autoradiography. J Neurosci 11:3556-3564.

Shetty AK, Hattiangady B, Rao MS, Shuai B (2010) Deafferentation enhances neurogenesis in the young and middle aged hippocampus but not in the aged hippocampus. Hippocampus. Advance online publication. Retrieved August 6, 2010. doi:10.1002/hipo.20776.

Suzuki Y, Schafer J, Farbman AI (1995) Phagocytic cells in the rat olfactory epithelium after bulbectomy. Exp Neurol 136:225-233.

Taupin P (2007) BrdU immunohistochemistry for studying adult neurogenesis: paradigms, pitfalls, limitations, and validation. Brain Res Rev 53:198-214.

Upadhyay UD, Holbrook EH (2004) Olfactory loss as a result of toxic exposure. Otolaryngol Clin North Am 37:1185-1207.

Valley MT, Mullen TR, Schultz LC, Sagdullaev BT, Firestein S (2009) Ablation of mouse adult neurogenesis alters olfactory bulb structure and olfactory fear conditioning. Front Neurosci 3:51.

Wagner W, Bork S, Horn P, Krunic D, Walenda T, Diehlmann A, Benes V, Blake J, Huber FX, Eckstein V, Boukamp P, Ho AD (2009) Aging and replicative senescence have related effects on human stem and progenitor cells. PLoS One 4:e5846.

Wakabayashi Y, Ichikawa M (2007) Distribution of Notch1-expressing cells and proliferating cells in mouse vomeronasal organ. Neurosci Lett 411:217-221.

Weiler E (2005) Postnatal development of the rat vomeronasal organ. Chem Senses 30[Suppl 1]:i127-i128.

Weiler E, Farbman AI (1997) Proliferation in the rat olfactory epithelium: age-dependent changes. J Neurosci 17:3610-3622.

Weiler E, Farbman AI (1998) Proliferation decrease in the olfactory epithelium during postnatal development. Ann N Y Acad Sci 855:230-234.

Weiler E, McCulloch MA, Farbman AI (1999) Proliferation in the vomeronasal organ of the rat during postnatal development. Eur J Neurosci 11:700-711.

Whitman MC, Greer CA (2009) Adult neurogenesis and the olfactory system. Prog Neurobiol 89:162-175.

Wu HH, Ivkovic S, Murray RC, Jaramillo S, Lyons KM, Johnson JE, Calof AL (2003) Autoregulation of neurogenesis by GDF11. Neuron 37:197-207.

Yankner BA, Lu T, Loerch P (2008) The aging brain. Annu Rev Pathol 3:41-66.

Yoshida-Matsuoka J, Matsuoka M, Costanzo RM, Ichikawa M (2000) Morphological and histochemical changes in the regenerating vomeronasal epithelium. J Vet Med Sci 62:1253-1261. 